\title{
Çelik Lif Katkılı Alüminyum Tüp İçine Beton Doldurulmuş Kirişlerin Eğilme Dayanımlarının İncelenmesi
}

\author{
Namık YALTAY*1, Demet YAVUZ², Soner GÜLER ${ }^{3}$ \\ ${ }^{1,2,3}$ Mühendislik Fakültesi, İnşaat Mühendisliği Bölümü, Van Yüzüncü Yıl Üniversitesi, Van
}

Geliş tarihi: 22.12.2020 Kabul tarihi: 31.03.2021

Öz

Çelik tüp içine beton doldurulmuş (ÇTBD) kirişlerin özellikle yüksek yapılarda ve köprü kirişlerinde kullanımı gün geçtikçe artmaktadır. Ancak, son yıllarda normal ve paslanmaz çelik yerine daha hafif ve ucuz olan alüminyum tüp içine beton doldurulmuş (ATBD) kirişler inşaat uygulamalarında yaygın bir şekilde kullanılmaktadır. Bu çalışmanın amacı çelik lif katkılı dikdörtgen en kesitli ATBD kirişlerin moment ve süneklik kapasitelerinin incelenmesidir. Çelik liflerin hacimsel lif oranları \%0,5 ve \%1,5 olarak, alüminyum tüp et kalınlıkları ise 2 ve $4 \mathrm{~mm}$ olarak seçilmiştir. Çalışma sonucunda, içi boş alüminyum tüplerin içine beton doldurulmasının ATBD kirişlerin dayanım ve süneklik kapasitelerini önemli oranda artırdığı belirlenmiştir. Çelik liflerin ATBD kirişlerin moment kapasitelerini arttırmada etkileri oldukça sınırlıyken, ATBD kirişlerin süneklik kapasitelerini arttırmada çok daha fazla etkili oldukları görülmüştür. Ayrıca, çelik lif hacimsel oranı \%0,5'den \%1,5'a çıkarıldığı zaman ATBD kirişlerin daha fazla elastik ötesi deformasyon yaptıkları ve bundan dolayı süneklik kapasitesindeki artışların daha belirgin olduğu belirlenmiştir.

Anahtar Kelimeler: Betonla doldurulmuş alüminyum tüp, Çelik lif, Eğilme dayanımı, Süneklik

\section{Flexural Behaviour of Steel Fiber Reinforced Concrete-Filled Aluminum Tube Beams}

\begin{abstract}
Nowadays, the use of concrete filled steel tube (CFST) beams is increasing especially in high structures and bridge beams. However, concrete filled aluminum tube (CFAT) beams that are lighter and cheaper than normal and stainless steel, are widely used in construction applications in recent years. The aim of this study is to examine the moment and ductility capacities of steel fiber reinforced rectangular CFAT beams. The volumetric ratios of steel fibers were selected as $0.5 \%$ and $1.5 \%$ and aluminum tube wall thicknesses were chosen as 2 and $4 \mathrm{~mm}$. The results show that filling concrete into hollow aluminum tubes significantly increase the strength and ductility capacities of CFAT beams. While the effects of steel fibers in increasing the moment capacity of CFAT beams are quite limited, it has been observed that they are much more effective in enhancing the ductility capacity of CFAT beams. In addition, when the steel
\end{abstract}

*Sorumlu yazar (Corresponding author): Namık YALTAY,namikyaltay@yyu.edu.tr 
fiber ratio was increased from $0.5 \%$ to $1.5 \%$, it was obtained that CFAT beams exhibit more inelastic deformation and therefore the increase in ductility capacity was more pronounced.

Keywords: Concrete filled aluminum tube, Steel fiber, Flexural strength, Ductility

\section{GíRiș}

Çelik tüp içine beton doldurulmuş (ÇTBD) kolon ve kiriş yapı elemanları günümüzde yüksek binalarda kullanımı gün geçtikçe artmaktadır. ÇTBD kiriş elemanlarının inşaat uygulamalarında yaygın olarak kullanılan çelik ve betonarme kiriş elemanlara göre bazı avantajlı özellikleri bulunmaktadır [1]. ÇTBD kiriş elemanlarda çelik ve betonun yerleşim düzeni kesitin dayanım ve rijitlik özellikleri açısından daha optimum bir çözüm sunmaktadır. Çeliğin ÇTBD kesitin en dışına yerleştirilmesi çekme gerilmelerini karşılamada daha etkin bir davranış sergilemesini sağlamaktadır. Bunun yanında, betondan daha büyük elastisite modülüne sahip olan çeliğin kesitin en dışına yerleştirilmesi nedeniyle ÇTBD kesitin eğilme rijitliği önemli oranda artmaktadır [2]. Çelik tüp içine yerleştirilen beton çelik tüpte oluşabilecek yerel ve tümden burkulmaları geciktirmektedir. Buna ilave olarak, çelik tüpün çekirdek betona uyguladığı yanal sargılama sayesinde çekirdek betonun dayanım ve süneklik kapasitesi artmaktadır. ÇTBD yapı elemanlarında etriye gibi enine donatı kullanılmadığı için birleşim bölgelerinde karşılaşılan sık donatı düzeni gibi sorunlarla karşılaşılmaz [3]. Bugüne kadar, ÇTBD kirişlerin eğilme davranışlarını inceleyen birçok çalışma yapılmıştır [4-5]. Araştırmacılar tarafından elde edilen test sonuçlarına göre, CFST kirişler, geleneksel betonarme (BA) kirişlere kıyasla, nihai yüklere kadar daha yüksek seviyede kompozit etki ve sünek davranış göstermişlerdir [6-8]. Dahası, çelik tüpün beton ile doldurulmasının çeliğin burkulma direncini ve dolayısıyla içi boş ÇTBD kirişlerin eğilme dayanımlarını, tokluk ve süneklik kapasitelerini önemli oranda arttırdığı belirtilmiştir [9-12]. ÇTBD kiriş elemanların daha sünek davranış sergilemelerini sağlamak amacıyla uygulamada farklı özelliklere sahip çelik ve sentetik liflerin betona katılması oldukça bilinen bir yöntemdir [13]. İki ucu kancalı çelik lifler iki ucunun kancalı olması sayesinde deprem enerjilerini sönümlemede sentetik liflere nazaran daha etkin bir davranış sergilerler. Özellikle eğilme etkisi altındaki kirişlerin ilk tepe yükü aşıldıktan sonra kırılma anına kadar çelik lifler köprüleme etkisi göstererek çatlakların kontrolsüz ve hızlı ilerleyişini önemli oranda sınırlarlar [12-14]. Bundan dolayı, çelik lif katkılı ÇTBD kirişler lif katkısız kontrol numuneye kıyasla kırılma anına kadar daha fazla yerdeğiştirme yaparak daha sünek bir davranış sergilerler. Buna bağlı olarak, çelik lif katkılı ÇTBD kirişlerin lif katkısız kontrol kirişlere kıyasla kırılma anına kadar enerji yutma (tokluk) kapasiteleri daha yüksek olur. ÇTBD kirişlerde şimdiye kadar en yaygın kullanılan çelik tipleri normal karbon çeliği ve paslanmaz çeliklerdir [14-15]. Son yıllarda, normal ve paslanmaz çelik yerine daha hafif ve ucuz olan Alüminyum tüp içine beton doldurulmuş (ATBD) kirişlerin kompozit yapılarda kullanımı oldukça popüler hale gelmiştir [16]. Alüminyum, doğada bileşik halde bulunan ve yerkabuğunun yaklaşık \%8'ini oluşturan bir malzemedir. Alüminyum üretiminin en önemli hammaddesi Boksit mineralidir ve yaklaşık olarak \%30-60 alüminyum oksit içerir [17]. Ülkemizde alüminyum işleme kapasitesi yaklaşık olarak 280.000- 300.000 ton/y1l civarındadır [18-20]. Ülkemizde alüminyum hammaddesi oldukça bol olmasına rağmen, alüminyum malzemesinin inşaat uygulamalarında taşıyıcı olarak kullanımı oldukça sınırlıdır. Bu çalışmanın ATBD kirişlerin eğilme etkileri altında davranışının daha iyi anlaşılması için literatüre önemli bir katkı sağlaması beklenmektedir. $\mathrm{Bu}$ çalışmada içi boş dikdörtgen en kesitli alüminyum tüpün yanı sıra içine sade beton ve çelik lif katkılı beton doldurulmuş ATBD kirişlerin dört noktalı yükleme altında eğilme dayanımları ve süneklik kapasiteleri belirlenmeye çalışılmıştır. Çalışmada 2 ve $4 \mathrm{~mm}$ et kalınlığına sahip ATBD kirişler kullanılmıştır. Her bir et kalınlığı için bir adet içi boş, bir adet sade betonla doldurulmuş ve iki adet çelik lif katkılı olmak üzere toplam 8 adet kiriş numunesi test edilmiştir. Çalışma sonucunda içi 
boş tüplerin sade betonla ve $\% 0,5$ ve $\% 1,5$ hacimsel lif oranına sahip çelik lif katkılı betonla doldurulmasının ATBD kirişlerin dayanım ve süneklik kapasitelerine hangi oranda katkı sağladıkları belirlenmeye çalışılmıştır.

\section{MATERYAL VE METOT}

\subsection{Materyal}

$\mathrm{Bu}$ çalışma kapsamında içi boş ve beton doldurulmuş ATBD kirişlerin eğilme dayanımlarını belirlemek için kullanılan malzeme ve yöntemler aşağıda belirtilmiştir.

\subsection{1. Çimento}

Çalışmada, Van Aşkale çimento fabrikasında üretilen TS EN 197-1 [21] uygun CEM I 42.5 R tipi Portland Çimentosu kullanılmıştır. Çimentonun fiziksel ve kimyasal analiz sonuçları Çizelge 1'de verilmiştir.

Çizelge 1. Çimentonun fiziksel ve kimyasal özellikleri

\begin{tabular}{|c|c|c|c|}
\hline \multicolumn{2}{|l|}{ Fiziksel özellikler } & $\begin{array}{l}\text { Kimyasal } \\
\text { özellikler }\end{array}$ & $(\%)$ \\
\hline $\begin{array}{l}\text { Özgül ağırlık } \\
\left(\mathrm{gr} / \mathrm{cm}^{3}\right)\end{array}$ & 3,09 & $\mathrm{SiO}_{2}$ & 18,97 \\
\hline $\begin{array}{l}\text { Özgül yüzey } \\
\left(\mathrm{cm}^{2} / \mathrm{gr}\right)\end{array}$ & 3728 & $\mathrm{Al}_{2} \mathrm{O}_{3}$ & 5,0 \\
\hline $\begin{array}{l}\text { Priz başlangıcı } \\
(\mathrm{dk})\end{array}$ & 185 & $\mathrm{Fe}_{2} \mathrm{O}_{3}$ & 3,22 \\
\hline Priz sonu (dk) & 235 & $\mathrm{CaO}$ & 59,98 \\
\hline $\begin{array}{l}0,045 \mathrm{~mm} \text { elekte } \\
\text { kalıntı }(\%)\end{array}$ & 3,2 & $\mathrm{MgO}$ & 2,84 \\
\hline $\begin{array}{l}0,090 \mathrm{~mm} \text { elekte } \\
\text { kalıntı }(\%)\end{array}$ & 0,1 & $\mathrm{SO}_{3}$ & 2,61 \\
\hline Yoğunluk $\left(\mathrm{gr} / \mathrm{cm}^{3}\right)$ & 990 & $\mathrm{Na}_{2} \mathrm{O}$ & - \\
\hline \multirow[t]{2}{*}{$\begin{array}{l}\text { Hacim } \\
\text { Genleşmesi (mm) }\end{array}$} & 1 & $\mathrm{Cl}$ & 0,016 \\
\hline & & $\begin{array}{c}\text { Kizdırma } \\
\text { kayb1 }\end{array}$ & 3,6 \\
\hline
\end{tabular}

\subsubsection{Agrega}

Bu çalışmada ATBD kirişlerin içine dökülen beton üretiminde Van yöresine ait kireçtaşı agregası kullanılmış olup, agreganın maksimum tane çapı 12 mm'dir. Agrega granülometrisi TS $706 \mathrm{EN}$ 12620 [23]'ye göre belirlenmiştir. Deneylerde, 0-5 mm kırma kum ve 5-12 mm kırma taş olmak üzere iki farklı boyutta agrega kullanılmıştır. Agregaların fiziksel özellikleri Çizelge 2'de verilmiştir.

Çizelge 2. Agregaların fiziksel özellikleri

\begin{tabular}{|l|c|c|}
\hline & \multicolumn{2}{|c|}{ Agrega Grubu } \\
\hline Özellikler & $0-5 \mathrm{~mm}$ & $5-12 \mathrm{~mm}$ \\
\hline Özgül Ağırlık & 2,69 & 2,59 \\
\hline Su Emme Oranı (\%) & 0,45 & 0,23 \\
\hline
\end{tabular}

\subsubsection{Lifler}

Çalışma kapsamında $30 \mathrm{~mm}$ uzunluğunda $0,75 \mathrm{~mm}$ çapında narinlik oranı (L/d) oranı 40 olan Dramix iki ucu kancalı çelik lifler kullanılmış olup, liflerin teknik özellikleri Çizelge 3'te verilmiştir. Lifler beton karışımlarına hacimsel olarak \%0,5 ve \%1,5 oranında katılmışlardır.

Çizelge 3. Çelik liflerin teknik özellikleri

\begin{tabular}{|l|c|}
\hline Teknik özellikler & Çelik lif \\
\hline Telin uzunluğu $(\mathrm{mm})$ & 30 \\
\hline Telin çap1 $(\mathrm{mm})$ & 0.75 \\
\hline Narinlik oranı $(\%)$ & 40 \\
\hline Çekme dayanımı $(\mathrm{MPa})$ & 1100 \\
\hline Elastisite modülü $(\mathrm{MPa})$ & 200000 \\
\hline
\end{tabular}

\subsubsection{Kimyasal Katkı}

Lif katkılı beton üretimi sırasında, betonun işlenebilirliğini artırmak amacı ile yeni nesil süper akışkanlaştırıcı (SA) katkı kullanılmıştır. SA katkı hacimsel olarak \%0,5 ve \%1,5 çelik lif içeren tüm karışımlarda çimento ağırlığının \%0,5 ve \%1'i olacak şekilde kullanılmıştır. SA katkı malzemesine ait özellikler Çizelge 4'te verilmiştir.

Çizelge 4. Süper akışkanlaştırıcının teknik özellikleri

\begin{tabular}{|l|l|}
\hline Malzemenin Yapıs1 & Polikarboksilik Eter Esasl1 \\
\hline Renk & Kahverengi \\
\hline Yoğunluk & $1,09 \mathrm{~kg} /$ litre \\
\hline Klor içeriği \% & $<0,1$ \\
\hline Alkali içeriği \% & $<3$ \\
\hline
\end{tabular}




\subsubsection{Beton Karışımlarının Hazırlanması}

$\mathrm{Bu}$ çalışmada kullanılacak olan betonun hedef basınç dayanımı $30 \mathrm{MPa}$ olarak belirlenmiştir. Beton karışımlarının hazırlanması işlemi $40 \mathrm{dm}^{3}$ kapasiteli pan tipi mikserde gerçekleştirilmiştir. Beton miksere, ilk olarak agrega ve çimento eklenerek 3 dakika kuru olarak karıştırılmıştır. Daha sonra su ve SA katk1 eklenerek 2 dakika daha karıştırılmıştır. Son olarak karışıma lifler eklenerek 2 dakika daha karıştırılmıştır. Hazırlanan karışımlarda, C30/37 betonu için çimento miktarı $380 \mathrm{~kg} / \mathrm{m}^{3}$ ve su/bağlayıcı $(\mathrm{S} / \mathrm{B})$ oran1 ise 0,47 olarak sabit tutulmuştur. Çelik liflerin karışım esnasında topaklanmasını önlemek amacıyla \%0,5 ve $\% 1,5$ çelik lif katkılı beton karışımlarında SA katk1 oran1 sirasiyla $\% 0,5$ ve $\% 1$ olarak belirlenmiştir. Tüm karışımlarda, çimento miktarı ve su/çimento oranı sabit tutulmuştur. ATBD kiriş beton karışımlarının hazırlanmasında kullanılan malzeme ve miktarları Çizelge 5’te verilmiştir.

Çizelge 5. Beton karıșım oranları

\begin{tabular}{|c|c|c|c|c|c|c|c|c|}
\hline $\begin{array}{c}\text { Numune } \\
\text { kodu }\end{array}$ & Numune Adı & S/B & Çimento $\mathbf{( k g})$ & $\begin{array}{c}\text { Lif } \\
(\mathbf{\%})\end{array}$ & $\begin{array}{c}\text { Su } \\
(\mathbf{k g})\end{array}$ & $\begin{array}{c}\text { Agrega } \\
\mathbf{0 - 5} \mathbf{~ m m} \\
\mathbf{( k g})\end{array}$ & $\begin{array}{c}\text { Agrega } \\
\mathbf{5 - 1 2} \mathbf{~ m m} \\
\mathbf{( k g})\end{array}$ & $\begin{array}{c}\text { SA } \\
(\boldsymbol{\%})\end{array}$ \\
\hline KO & C30_Kontrol & 0,47 & 380 & - & 180 & 760 & 1090 & - \\
\hline K0,5\% & C30_Çelik_0,5\% & 0,47 & 380 & 0,5 & 180 & 760 & 1090 & 0,5 \\
\hline K1,5\% & C30_Çelik_1,5\% & 0,47 & 380 & 1,5 & 180 & 760 & 1090 & 1,0 \\
\hline
\end{tabular}

\subsection{Metot}

Çalı̧̧mada, içi boş, sade beton ve çelik lif katkılı dikdörtgen en kesitli ATBD kompozit kirişlerin dört noktalı yükleme altında eğilme davranışları incelenmiştir. Bu amaçla, bir adet kontrol ve iki farklı hacimsel lif oranı $(\% 0,5$ ve \%1,5) olmak üzere toplamda 3 farklı beton karışımı hazırlanmıştır. Karıştırma işlemi sonunda taze betonlar basınç dayanımı deneyi için $150 \mathrm{~mm} \mathrm{x}$ $150 \mathrm{~mm}$ x $150 \mathrm{~mm}$ boyutlarında küp kalıplara konulmuş ve kalıpta 24 saat bekletilmiștir. Kalıptan çıkarılan numuneler, $23 \pm 2^{\circ} \mathrm{C}$ sıcaklıktaki kür havuzuna konularak deney gününe kadar bekletilmiştir. Kür süresi tamamlanan küp numuneler üzerinde basınç dayanımı deneyleri gerçekleştirilmiştir. İçi boş ATBD kirişlerin alt tarafları $10 \mathrm{~mm}$ et kalınlıklı sac plaka ile vidalandıktan sonra hazırlanan beton karışımları kirişlerin içerisine doldurulmuştur. Doldurma işlemi yapıllırken her $30 \mathrm{~cm}$ 'de bir çubuk şişlerle betonlar sıkıştırılmış̧ır. Beton doldurma işlemi tamamlandıktan sonra kirişlerin üst yüzeyi mala ile düzeltilerek deneye hazır hale getirilmişlerdir. Çalışmada aynı zamanda, dört noktalı yükleme altında eğilme deneyleri yapılmıştır. ATBD kirişler üzerinde eğilme dayanımını belirlemek için 4 noktalı yükleme deneyleri gerçekleştirilmiştir. Eğilme dayanımı deneyleri TS EN 12390-5 [22] standardına göre yapılmış olup, deneylerde 100 $\mathrm{mm}$ yüksekliğinde, $60 \mathrm{~mm}$ eninde, $1000 \mathrm{~mm}$ uzunluğa sahip $(100 \times 60 \times 1000)$ boyutlarında dikdörtgen en kesitli alüminyum tüp kiriş numuneler kullanılmıştır. Kirişlerin oturduğu iki mesnet arası net açıklığ $900 \mathrm{~mm}$ alınmıştır. Numunelerin düşey deplasmanları kiriş orta noktasına yerleştirilen 1 adet düşey yer değiş̧irme ölçer (LVDT) yardımıyla ölçülmüştür. ATBD kirişlerin 4 noktalı yükleme altında deney düzeneği Şekil 1 de verilmiştir.

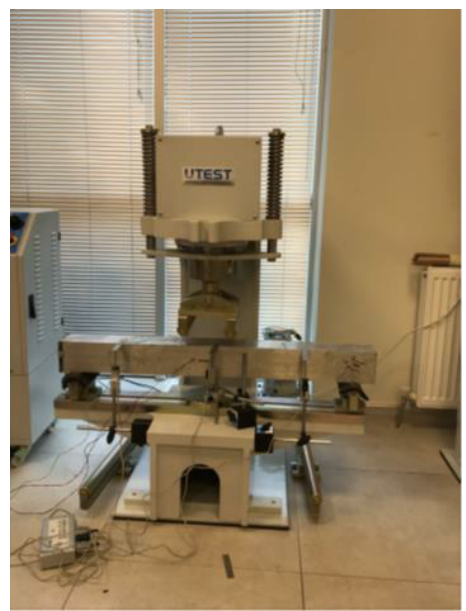

Şekil 1. ATBD kirişlerin dört noktalı yükleme altında deney düzeneği 


\section{BULGULAR VE TARTIŞMA}

\subsection{ATBD Kirişlerin Yük-Yer Değiştirme Grafikleri}

İçi boş, sade ve lif katkılı beton doldurulmuş ATBD kirişlerin yük-yer değiştirme ilişkileri Şekil 2 ve Şekil 3'de gösterilmiştir. İçi boş, sade ve lif katkılı beton doldurulmuş ATBD kirişlerin yük deplasman grafikleri kirişlerin kırılma yüküne karş1 gelen deplasman değerine kadar çizilmiştir. Ancak, yük-yerdeğiştirme grafiklerinde yükün aniden sıfıra düştüğü kısım LVDT'den sağlıklı okumalar yapılamadığı için göz önüne alınmamıştır. İçi boş alüminyum kirişler oldukça fazla sayıda yerel burkulmalarla veya tüp duvarlarının özellikle basınç bölgesinde yırtılmalar sonucu gevrek bir davranış göstererek nihai taşıma kapasitelerine ulaşmışlardır. İçi beton doldurulmuş ATBD kirişler ise daha az sayıda yerel burkulma yaparak içi boş kirişlere kıyasla çok daha sünek bir davranış göstererek nihai taşıma kapasitelerine ulaşmışlardır. Kirişlerin et kalınlıkları arttıkça kırılma anına kadar daha stabil bir davranış sergiledikleri gözlenmiştir.

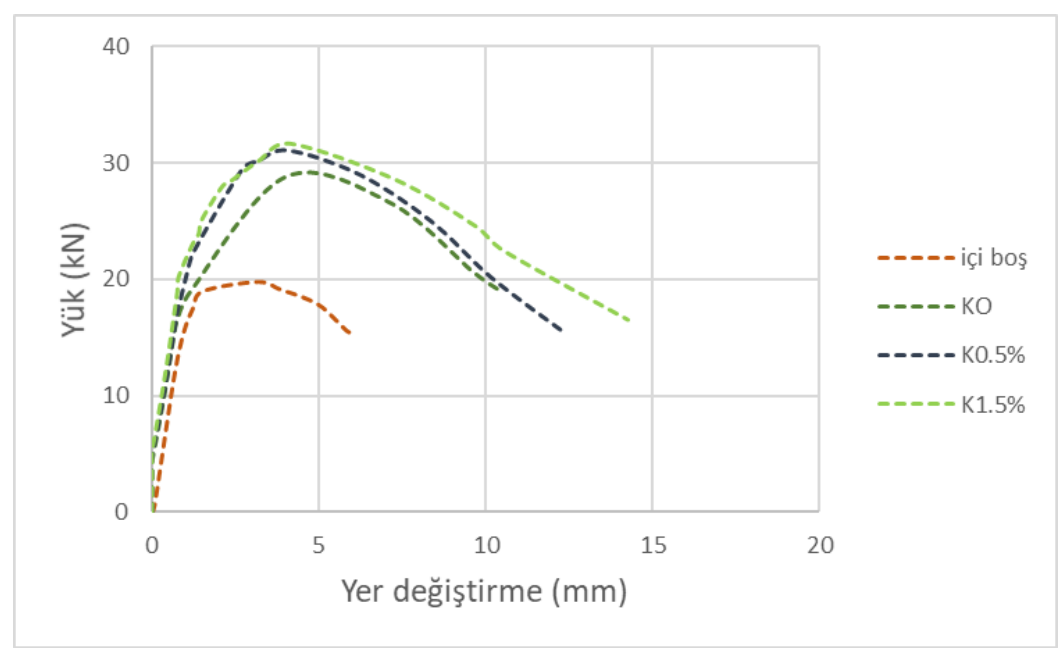

Şekil 2. 2 mm et kalınlıklı ATBD kirişlerin yük-yer değiştirme ilişkisi

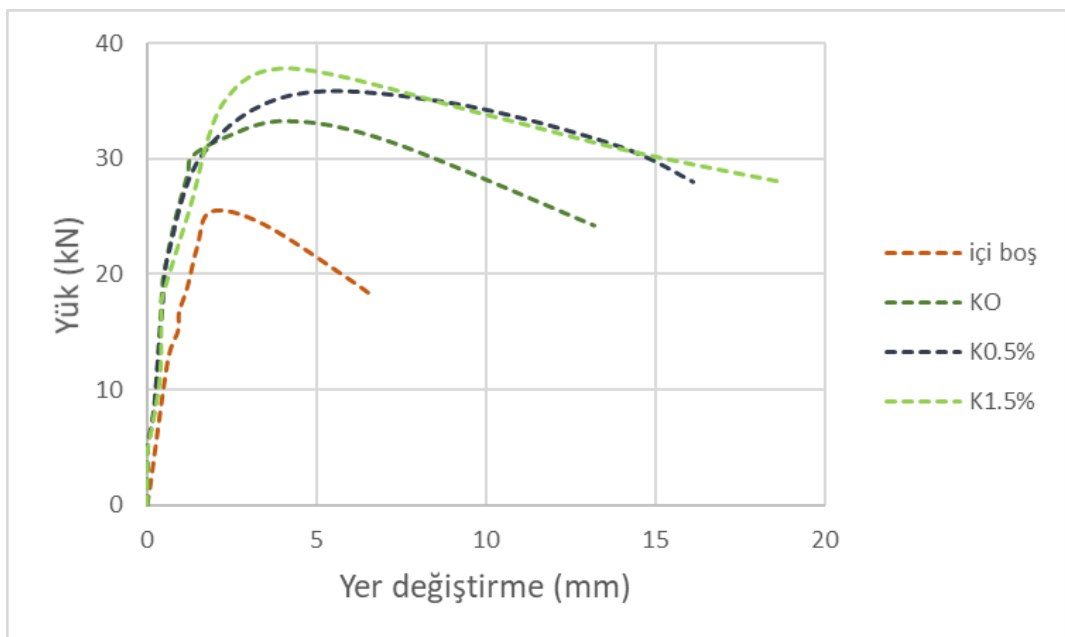

Şekil 3. 4 mm et kalınlıklı ATBD kirişlerin yük-yer değiştirme ilişkisi 


\subsection{ATBD Kirişlerin Eğilme Dayanımı ve Süneklik Kapasiteleri}

$\mathrm{Bu}$ çalışmada ATBD kirişlerin eğilme dayanımı, maksimum eğilme dayanımı ve süneklik faktörü değerleri Eşitlik 1-3'de gösterildiği gibi elde edilmiştir.

$$
\begin{aligned}
& M=\frac{7 \times P \times L_{s}}{40} \\
& M_{u}=\frac{7 \times P_{\max } \times L_{s}}{40} \\
& \mu=\frac{\delta_{u}}{\delta_{y}}
\end{aligned}
$$

Burada, $\mathrm{M}$ eğilme dayanımı (moment) değerini, $\mathrm{P}$ uygulanan yükü, Ls iki mesnet arasındaki etkili net açıklığı, Pmax maksimum eğilme yükünü, Mu ilk tepe yüküne karşı gelen maksimum moment kapasitesini, $\mu$ süneklik faktörünü, $\delta u$ nihai yerdeğiştirme değerini, $\delta$ y ilk tepe yüküne karşı gelen akma yerdeğiştirmesini göstermektedir. ATBD kirişlerin içi boş alüminyum kirişlere kıyasla eğilme dayanımı ve süneklik kapasitesindeki artı̧̧1 göstermesi açısından dayanım artış indeksi (SIF) süneklik artış indeksi (DIF) sırasıyla Eşitlik 4 ve 5'te verilmiştir. Bazı çalışmalarda süneklik faktörü ilk tepe yükü aşıldıktan sonra ilk tepe yükünün \%85'ine karş1 gelen yerdeğiştirme oranının ilk tepe yüküne karşı gelen oranı olarak verilmektedir [24]. Ancak, bu çalışmada liflerin elastik ötesi davranışa etkilerini daha uzun bir bölgede değerlendirebilmek için yükün aniden sıfıra doğru gitmeye başladığı noktaya karşı gelen yerdeğiştirme değeri nihai yerdeğiştirme değeri olarak kabul edilmiştir.

$$
\begin{gathered}
S I F=\frac{M_{\text {dolu }}}{M_{\text {bos }}} \\
D I F=\frac{\mu_{\text {dolu }}}{\mu_{\text {bos }}}
\end{gathered}
$$

İçi boş, sade ve lif katkılı beton doldurulmuş $2 \mathrm{~mm}$ ve $4 \mathrm{~mm}$ et kalınlığına sahip ATBD kirişlerin eğilme dayanımları, süneklik, SIF ve DIF değerleri sırasıyla Çizelge 6 ile Çizelge 7'de verilmiştir.

Çizelge 6 ve Çizelge 7'ye bakıldı̆̆ zaman içi boş kirişlere kıyasla, ATBD kirişlerin moment değerlerinde önemli artışların olduğu görülmüştür, İçi boş kirişlere kıyasla, sade beton doldurulmuş ATBD kirişin moment kapasitesindeki artış $2 \mathrm{~mm}$ kalınlığındaki ATBD kirişler için \%66,7 iken 4 mm kalınlığındaki ATBD kiriş için ise aynı değer $\% 67,38$ olarak elde edilmiştir. ATBD kirişlerin et kalınlığ 2 mm'den 4 mm'e çıktığı zaman ATBD kirişlerin ilk tepe yüküne kadar yerel burkulmaların daha az olması ve betona uygulanan yanal sargılama etkisinin daha büyük olmasından dolayı ATBD kirişlerin daha büyük eğilme dayanımlarına sahip oldukları görülmektedir. Ancak, sade beton doldurulmuş ATBD kirişlere $\% 0,5$ ve $\% 1,5$ hacimsel oranında çelik lif eklenmesi sonucu moment kapasitesindeki artışlar sınırlı kalmıştır. Sade beton doldurulmuş $2 \mathrm{~mm}$ kalınlıklı ATBD kirişlere kıyasla ise \%0,5 ve \%1,5 çelik lif katkılı $2 \mathrm{~mm}$ kalınlıklı ATBD kirişlerin moment kapasitelerindeki en büyük artışlar sirasiyla $\% 4,59$ ve $\% 7,07$ olmuştur. Sade beton doldurulmuş $4 \mathrm{~mm}$ kalınlıklı ATBD kirişlere kıyasla ise \%0,5 ve \%1,5 çelik lif katkılı $4 \mathrm{~mm}$ kalınlıklı ATBD kirişlerin moment kapasitelerindeki en büyük artışlar ise sırasıyla $\% 6,36$ ve $\% 8,37$ olmuştur. Buradan görüldüğ̈̈u gibi, çelik lifler $2 \mathrm{~mm}$ ve $4 \mathrm{~mm}$ et kalınlığına sahip ATBD kirişlerin eğilme dayanımı kapasitelerini en fazla sirasıyla $\% 7,07$ ve $\% 8,37$ oranında artırmıştır. Çelik lif katkısı sade beton doldurulmuş ATBD kirişlere kıyasla ATBD kirişlerin moment kapasitelerini kısmen yükseltmiş olsa da gözlenen artışın oldukça sınırlı kaldığı görülmektedir. Sonuç olarak içi sade betonla doldurulmuş tüplere kıyasla, içi çelik lif katkılı beton doldurulmuş ATBD kirişlerin moment kapasitelerindeki artışlar oldukça sınırlıdır. Bunun en önemli nedeni çelik liflerin ilk tepe yüküne kadar olan elastik bölgede çatlakları sınırlamada yeterince etkili olamamalarından kaynaklanmaktadır. Süneklik faktörünün 
hesaplanmasında süneklik değerleri $(\mu)$ kırılma anındaki düşey deplasmanın $\left(\delta_{\mathrm{u}}\right)$ akma anındaki deplasmana $\left(\delta_{\mathrm{y}}\right)$ oranı olarak verilmiştir. İçi boş kirişe kıyasla sade ve çelik lif katkılı ATBD kirişlerin süneklik değerlerindeki artışlar ATBD kirişlerin et kalınlığı ve hacimsel lif oranı arttıkça daha fazla olmuştur. İçi boş tüplere kıyasla sade, $\% 0,5$ ve \%1,5 çelik lif katkılı 2 mm et kalınlığına sahip ATBD kirişlerin süneklik faktörlerindeki artışlar sırasıly \%69,56, \%99,46 ve \%127,17 olmuştur. İçi boş tüplere kıyasla sade, \%0,5 ve $\%$ 1,5 çelik lif katkılı $4 \mathrm{~mm}$ et kalınlığına sahip ATBD kirişlerin süneklik faktörlerindeki artışlar ise sirasiyla \%93,47, \%134,67 ve $\% 167,84$ olmuştur. Sade beton doldurulmuş $2 \mathrm{~mm}$ kalınlıklı ATBD kirişlere kıyasla ise \%0,5 ve \%1,5 çelik lif katkılı 2 mm kalınlıklı ATBD kirişlerin süneklik kapasitelerindeki artışlar sırasıyla \%18,73 ve \%37,08 olmuştur. Sade beton doldurulmuş $4 \mathrm{~mm}$ kalınlıklı ATBD kirişlere kıyasla ise \%0,5 ve \%1,5 çelik lif katkılı 2 mm kalınlıklı ATBD kirişlerin süneklik kapasitelerindeki artışlar sırasıyla \%22,03 ve \%41,63 olmuştur. Moment kapasitesindeki artışı temsil eden SIF değerlerinin kalınlık ve hacimsel lif oranına bağlı değişimini gösteren grafikler Şekil 4'te verilmiştir. Süneklik kapasitesindeki artışı temsil eden DIF değerlerinin kalınlık ve hacimsel lif oranına bağlı değişimini gösteren grafikler ise Şekil 4b'da verilmiştir. Şekil 4a ve Şekil 4b'den görüldüğü gibi içi boş kirişlere kıyasla sade beton, \%0,5 ve $\% 1,5$ hacimsel lif oranına sahip kirişlerin SIF ve DIF değerlerindeki artışlar arasında doğrusal olarak artan bir ilişki vardır. Ancak, sade betonla doldurulmuş ATBD kirişlere kıyasla \%0,5 ve \%1,5 hacimsel lif oranına sahip ATBD kirişlerin SIF değerlerindeki artışlar yatay seyrederken, DIF değerlerindeki artışlar doğrusal olarak artmaya devam etmiştir. Bunun en önemli nedeni çelik liflerin ilk tepe yüküne kadar olan kısımda dayanım ve süneklik kapasitesine etkileri oldukça sınırlı kalmaktayken, ilk tepe yükü aşıldıktan sonra kırılma anına kadar çatlakları sinırlamada daha etkin bir rol oynamalarından kaynaklanmaktadır. Bundan dolayı, sade betona çelik lif eklenmesinin sade beton doldurulmuş ATBD kirişlerin moment kapasitelerini arttırmada oldukça sınırlı düzeyde katkı sağlarken, süneklik kapasitelerini önemli oranda arttırmaktadır. Ayrıca, bu durum çelik lif hacimsel oranı \%0,5, den \%1,5'a çıktığı zaman daha belirgin bir hal almaktadır. $2 \mathrm{~mm}$ et kalınlığına sahip ATBD kirişlere kıyasla $4 \mathrm{~mm}$ kalınlığa sahip numuneler kırılma anına kadar daha fazla düşey deplasman yaptıkları için daha fazla süneklik kapasitesine sahiptirler. Bundan dolayı, çelik liflerin hacimsel oranının \%0,5'den \%1,5' a çıkarılması durumunda çelik lifler ATBD kirişlerin kırılma anına kadar olan bölgede süneklik kapasitelerine daha fazla katk1 sunabilmektedirler.

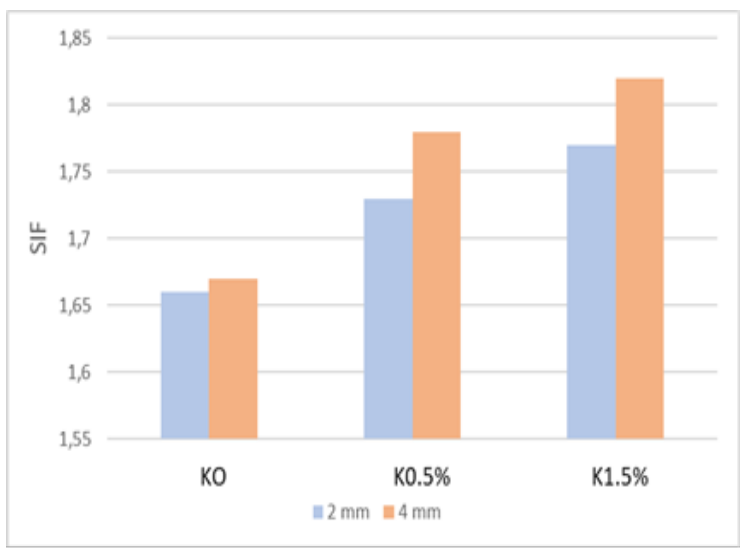

(a)

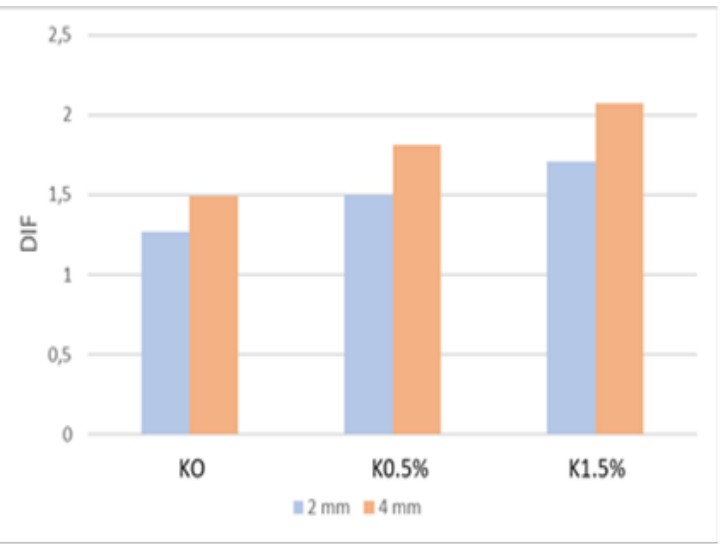

(b)

Şekil 4. SIF ve DIF değerlerinin et kalınlığı ve lif oranı ile değişimi 
Çizelge 6. 2 mm et kalınlıklı ATBD kirişlerin deney sonuçları

\begin{tabular}{|c|c|c|c|c|c|c|c|c|c|c|c|c|}
\hline $\begin{array}{l}\text { Numune } \\
\text { Kodu }\end{array}$ & $\begin{array}{c}\mathrm{HxB} \\
(\mathrm{mmxmm})\end{array}$ & $\begin{array}{c}\mathrm{t} \\
(\mathrm{mm})\end{array}$ & $\begin{array}{c}1 \\
(\mathrm{~mm})\end{array}$ & $\begin{array}{c}\text { Çelik } \\
\text { lif } \\
(\%)\end{array}$ & $\begin{array}{c}\text { Moment } \\
(\mathrm{kN}, \mathrm{m})\end{array}$ & $\begin{array}{l}\text { Moment } \\
\text { kapasitesi } \\
\text { artış } \\
(\%)\end{array}$ & $\begin{array}{c}\text { Akma } \\
\text { deplasmanı } \\
\left(\delta_{\mathrm{y}}\right)\end{array}$ & $\begin{array}{c}\text { Kırılma } \\
\text { anındaki } \\
\text { düşey } \\
\text { deplasman } \\
\left(\delta_{\mathrm{u}}\right)\end{array}$ & $\begin{array}{l}\text { Süneklik } \\
\text { faktörü } \\
(\mu)\end{array}$ & $\begin{array}{c}\text { Süneklik } \\
\text { kapasitesi } \\
\text { artış } \\
(\%)\end{array}$ & DIF & SIF \\
\hline İçi boş & $100 \times 60$ & 2 & 1000 & - & 3,16 & - & 3,28 & 6,04 & 1,84 & - & - & - \\
\hline KO & 100x60 & 2 & 1000 & - & 5,23 & 66,7 & 3,34 & 10,41 & 3,12 & 69,56 & 1,72 & 1,66 \\
\hline K0.5\% & $100 \times 60$ & 2 & 1000 & 0,5 & 5,47 & 74,2 & 3,37 & 12,36 & 3,67 & $\begin{array}{l}99,46 \\
\end{array}$ & 2,05 & 1,73 \\
\hline K1.5\% & $100 \times 60$ & 2 & 1000 & 1,5 & 5,60 & 78,3 & 3,41 & 14,27 & 4,18 & 127,17 & 2,36 & 1,77 \\
\hline
\end{tabular}

Çizelge 7. 4 mm et kalınlıklı ATBD kirişlerin deney sonuçları

\begin{tabular}{|c|c|c|c|c|c|c|c|c|c|c|c|c|}
\hline $\begin{array}{c}\text { Numune } \\
\text { Kodu }\end{array}$ & $\begin{array}{c}\mathrm{HxB} \\
(\mathrm{mmxmm})\end{array}$ & $\begin{array}{c}\mathrm{t} \\
(\mathrm{mm})\end{array}$ & $\begin{array}{c}1 \\
(\mathrm{~mm})\end{array}$ & $\begin{array}{l}\text { Çelik } \\
\text { lif } \\
(\%)\end{array}$ & $\begin{array}{c}\text { Moment } \\
(\mathrm{kN}, \mathrm{m})\end{array}$ & $\begin{array}{c}\text { Moment } \\
\text { kapasitesi } \\
\text { artış } \\
(\%)\end{array}$ & $\begin{array}{c}\text { Akma } \\
\text { deplasmanı } \\
(\delta y)\end{array}$ & 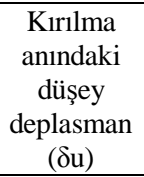 & $\begin{array}{c}\text { Süneklik } \\
\text { faktörüu } \\
(\mu)\end{array}$ & $\begin{array}{c}\text { Süneklik } \\
\text { kapasitesi } \\
\operatorname{artış~(\% )~}\end{array}$ & DIF & SIF \\
\hline İçi boş & $100 \times 60$ & 4 & 1000 & - & 4,23 & - & 3,37 & 6,71 & 1,99 & - & - & - \\
\hline $\mathrm{KO}$ & $100 \times 60$ & 4 & 1000 & - & 7,08 & 67,3 & 3,43 & 13,21 & 3,85 & 93,47 & 1,96 & 1,67 \\
\hline $\mathrm{K} 0,5 \%$ & $100 \times 60$ & 4 & 1000 & 0,5 & 7,53 & 70,3 & 3,45 & 16,12 & 4,67 & 134,67 & 2,40 & 1,78 \\
\hline $\mathrm{K} 1,5 \%$ & $100 \times 60$ & 4 & 1000 & 1,5 & 7,71 & 71,4 & 3,51 & 18,71 & 5,33 & 167,84 & 2,79 & 1,82 \\
\hline
\end{tabular}

\section{SONUÇLAR}

$\mathrm{Bu}$ çalışma ile çelik liflerin içi boş ve sade beton ile doldurulmuş ATBD kirişlerin moment ve süneklik kapasitelerinde ne gibi değişimler yaptığı belirlenmeye çalışılmıştır. Çalışma sonucunda elde edilen sonuçlar özetle aşağıdaki gibidir:

- İçi boş kirişlere kıyasla ATBD kirişlerin moment ve süneklik kapasitelerindeki artışlar oldukça yüksektir.

- Çelik liflerin sade betonla doldurulmuş ATBD kirişlerin moment kapasitelerine katkısı süneklik kapasitesine sağladığ1 katkıdan daha sınırlıdır.

- Çelik liflerin hacimsel lif oranı arttıkça ATBD kirişlerin süneklik kapasitesindeki artışlar moment kapasitesindeki artışa kıyasla daha belirgin olmaktadır.

- ATBD kirişlerin et kalınlıkları arttıkça daha iyi uygulanan yanal sargılama etkisi nedeniyle eğilme dayanımları ve süneklik kapasitelerindeki artışlar artmaktadır.

- Çelik lifler ilk tepe yükü aşıldıktan sonra kırılma anına kadar olan kısımda çatlakların kontrolsüz ve hızlı ilerleyişini sınırlamada elastik bölgeye nazaran daha etkilidirler.

\section{TEŞEKKÜR}

Bu çalışma 2018-FBA-6669 no'lu proje olarak, Van Yüzüncü Yıl Üniversitesi Araştırma Projeleri Birimi Tarafından desteklenmiştir.

\section{KAYNAKLAR}

1. Cai, S.H., 1988. Ultimate Strength of ConcreteFilled Tube Columns. Composite Construction in Steel and Concrete. Proceedings of the Engineering Foundation Conference, 702-727.

2. Gao, J., Sun, W., Morino, K., 1997. Mechanical Properties of Steel Fiberreinforced, High-strength, Lightweight Concrete, Cement Concrete Compos, 19(4), 307-13.

3. Gardner, N.J., Jacobson, E.R., 1967. Structural Behavior of Concrete Filled Steel Tubes, Journal of the American Concrete Institute. 64(11), 404-413.

4. Lu, Y., Kennedy, D., 1994. Flexural Behavior of Concrete-Filled Hollow Structural Sections. Canadian Journal of Civil Engineering, 21(1), 111-130.

5. O'Shea, M.D., Bridge, R.Q., 1997. Local Buckling of Thin-Walled Circular Steel Sections With or Without Lateral Restraint, Research Report No. R740, School of Civil 
Engineering, University of Sydney, Sydney, Australia.

6. Moon, J., Roeder, C.W., Lehman, D.E., Lee, H.E., 2012. Analytical Modeling of Bending of Circular Concrete-filled Steel Tubes. Engineering Structures, 42, 349-361.

7. Nieuwoudt, P.D., Babafemi, A.J., Boshoff., W.P., 2017. The Response of Cracked Steel Fibre Reinforced Concrete Under Various Sustained Stress Levels on Both the Macro and Single Fibre Level, Constr. Build. Mater, 156, 828-843.

8. Lu, Y., Liu, Z., Li, S., Hu., J., 2018. Axial Compression Behavior of Hybrid Fiber Reinforced Concrete Filled Steel Tube Stub Column, Constr. Build. Mater. 174, 96-107.

9. Dong, M., Elchalakani, M., Karrech, A., Fawzia, S., Ali, M.S.M., Yang, B., Xu, S.Q., 2019. Circular Steel Tubes Filled with Rubberised Concrete Under Combined Loading. Journal of Constructional Steel Research, 162, 105613.

10. Liu, Z., Lu, Y., Li, S., Liao, J., 2019. Axial Behavior of Slender Steel Tube Filled with Steel-fiber-reinforced Recycled Aggregate Concrete. Journal of Constructional Steel Research, 162, 105748

11. Xu, L., Lu, Q., Chi, Y., Yang, Y., Yu, M., Yan, Y., 2019. Axial Compressive Performance of UHPC Filled Steel Tube Stub Columns Containing Steel-polypropylene Hybrid Fiber. Construction and Building Materials, 204, 754-767.

12. Schneider, S.P., 1998. Axially Loaded Concrete-Filled Steel Tubes, Journal of Structural Engineering, ASCE, 124(10), 1125-1138.

13. Shakir-Khalil, H., Mouli, M., 1990. Further Tests on Concrete-Filled Rectangular HollowSection Columns, The Structural Engineering, 68(20), 405-413.

14. Saatcioglu., M., Razvi., S.R., 1992. Strength and Ductility of Confined Concrete, Journal of Structural Engineering, ASCE, 118(6), 1590-1607.

15. Tomii, M., Sakino, K., 1979. Experimental Studies on the Ultimate Moment of Concrete Filled Square Steel Tubular Beam-Columns,
Transactions of the Architectural Institute of Japan, no. 275, 55-63.

16. Yu, Q., Tao, Z., Wu, Y.X., 2008. Experimental Behaviour of High Performance ConcreteFilled Steel Tubular Columns, Thin-Walled Structures, 46(4), 362-370.

17.Zhang, S., Zhou, M., 2000. Stress-Strain Behavior of Concrete-Filled Square Steel Tubes, Composite and Hybrid Structures. Proceedings of the Sixth ASCCS International Conference on Steel-Concrete Composite Structures, March 22-24, Los Angeles, California, 403-409.

18. Zhao, H.L, Zhao, Y.G., 2010. Suggested Empirical Models for The Axial Capacity of Circular CFT Stub Columns, Journal of Constructional Steel Research, 66(6), 850-62.

19. Kim, Y.H., You, S.K., Jung, J.H., Yoon, S.J., 2006. Strengthening Effect of the Shear Key on the Flexural Behavior of Concrete Filled Circular Tube, Steel Struct, 6, 183-190.

20. Alberti, M.G., Enfedaque, A., Galvez., J.C., 2018. A Review on the Assessment and Prediction of the Orientation and Distribution of Fibres for Concrete, Compos. B Eng. 151, 274-290.

21. TS EN 197-1, Çimento- Bölüm 1: Genel Çimentolar- Bileşim, Özellikler ve Uygunluk Kriterleri, TSE, Ankara, 2002.

22. TS EN 12390-5, Beton - Sertleşmiş Beton Deneyleri Bölüm 5: Deney Numunelerinde Eğilme Dayanımının Tayini, TSE, Ankara, 2010.

23. TS 706 EN 12620+A1, Beton Agregaları, TSE, Ankara, 2009.

24. Meda, A., Minelli, F., Plizzari, G.A., 2012. Flexural Behaviour of RC Beams in Fibre Reinforced Concrete. Composites Part B: Engineering, 43(8), 2930-2937. 
